\title{
ANALYSIS ON THE TIME-VARYING GAP OF DISCRETE TIME-VARYING LINEAR SYSTEMS
}

\author{
LIU LIU AND YUFENG LU
}

Abstract. This paper is devoted to give some analysis on the time-varying (TV) gap of discrete time-varying linear systems in the frame work of nest algebra. It is shown that the TV gap has no advantage over gap metric in stability and robustness analysis on the single-sided discrete time-axis $\mathbb{N}$, while it stands out on the whole time-axis $\mathbb{Z}$.

Mathematics subject classification (2010): 47L35, 47N70.

Keywords and phrases: Time-varying gap, closed-loop stability, double-sided signal space, time-varying system, nest algebra.

\section{REFERENCES}

[1] G. Zames And A. El-SAKKary, Unstable Systems and Feedback: The Gap Metric, Proc. 18th Allerton Conf., 1980, 380-385.

[2] A. EL-SAKKARY, The gap metric: robustness of stabilization of feedback systems, IEEE Trans. Automat. Control 30 (1985), 240-247.

[3] T. T. Georgiou, On the computation of the gap metric, Systems and Control Letters 11 (1988), 253-257.

[4] T. T. Georgiou, M. C. SMith, Optimal robustness in the gap metric, IEEE Trans. Automat. Control 6 (1990), 673-686.

[5] C. Foias, T. T. Georgiou And M. C. SMith, Robust stability of feedback systems: a geometric approach using the gap metric, SIAM J. Control Optim. 31 (1993), 1518-1537.

[6] M. CAntoni And G. Vinnicombe, Linear feedback systems and graph topology, IEEE Trans. Automat. Control 47 (2002), 710-719.

[7] U. Jonsson, M. CAntoni And C. Y. CAO, On structured robustness analysis for feedback interconnections of unstable systems, 47th IEEE Conf. Decision \& Control, 2008, 351-356.

[8] S. M. Djouadi, C. D. Charalambous, Time-varying optimal disturbance minimization in presence of plant unvertanity, SIAM J. Control Optim. 48 (2010), 3354-3367.

[9] L. LiU, Y. LU, Stabilizability, representations and factorizations for the time-varying linear system, System \& Control Letters 66 (2014), 58-64.

[10] S. M. DJOUADI, On robustness in the gap metric and coprime factor uncertainty for LTV systems, Systems \& Control Letters 80 (2015), 16-22.

[11] L. LiU, Y. Lu, Stability analysis for time-varying systems via quadratic constraints, Systems \& Control Letters 60 (2011), 832-839.

[12] A. FeINTUCH, On the strong stabilization of slowly time-varying linear systems, Systems and Control Letters 61 (2012), 112-116.

[13] A. FeIntuch, Robust Control Theory in Hilbert Space, Springer-Verlag, 1998.

[14] A. Feintuch, The time-varying gap and coprime factor perturbations, Math. Control Signals Systems 8 (1995), 352-374.

[15] S. M. DJouAd, Commutant lifting for linear time-varying systems, American Control Conference, June 10-12(2009), 4067-4072.

[16] L. LIU, Y. LU, Commutant lifting for optimal controlof time-varying systems, Communications in Mathematical Research 28, 3 (2012), 252-264. 
[17] T. T. Georgiou, M. C. Smith, Intrinsic difficulties in using the double-infinite time axis for inputoutput control theory, IEEE Transactions on Automatic Control 40 (1995), 516-518.

[18] B. JАСОВ, What is the better signal space for discrete-time systems: $\ell_{2}(\mathbb{Z})$ or $\ell_{2}\left(\mathbb{N}_{0}\right)$, SIAM J. Control Optim. 43 (2005), 1521-1534.

[19] A. Feintuch, A. Markus, A general time-varying estimation and control problem, Math. Control Signals Systems 17 (2005), 217-230.

[20] M. CANTONI, U. JonsSON, AND S. Z. KHONG, Robust stability analysis for feedback interconnections of time-varying linear systems, SIAM J. Control Optim. 51 (2013), 353-379.

[21] S. Z. Khong, M. CANTONI, Gap metrics for time-varying linear systems in a continuous-time setting, Systems \& Control Letters 70 (2014), 118-126.

[22] J. B. CONWAY, A course in functional analysis, Springer, 1990.

[23] K. R. DAVidson, Nest Algebras, Longman Scientific and Technical, UK, 1988.

[24] W. N. DALE, M. C. SMIth, Stabilizanbility and existence of system representation for discrete-time time-varying system, SIAM J. Control Optim. 31 (1993), 1538-1557.

[25] A. FeinTUCH, On strong stabilization for linear time-varying systems, Systems \& Control Letters 54 (2005), 1091-1095. 